\title{
A infância e o brincar na cultura digital
}

\author{
Edvaldo Souza Couto*
}

\section{Resumo}

A partir de estudos que discutem a cibercultura, a infância e o brincar na cultura digital, esse artigo refletirá sobre a cultura lúdica infantil na era das conexôes. O caminho percorrido foi buscar pistas das características mais marcantes da cibercultura para, em seguida, observá-las na cultura lúdica infantil. $\mathrm{O}$ argumento principal é o de que as crianças que fazem parte da chamada Geração Net, que nasceram inseridas no contexto das tecnologias de informação e comunicação, participam ativamente do mundo digital, vivem, sobretudo por meio das tecnologias móveis, a conectividade. Nesse contexto, tocar em telas e brincar são modos especiais de construir subjetividades e existências, de viver e produzir a cultura infantil. $\mathrm{O}$ artigo conclui que o toque nas mais diversas telas, muitas delas na palma da mão, traduzem muito do que é o brincar e o lúdico na atualidade. Tocar em telas digitais é o mais expressivo modo lúdico que as crianças encontram para elaborar a vida por meio de alegrias e prazeres privados e coletivos nos domínios da rede.

Palavras-chave: Infância. Ludicidade. Cultura digital.

\footnotetext{
* Doutor em Educação pela Universidade Estadual de Campinas (UNICAMP). Professor na Graduação e na Pós-Graduação em Educação, na Universidade Federal da Bahia (UFBA). Pesquisador com bolsa de produtividade do CNPq.
} 


\section{Introdução}

É cada vez mais comum encontrar em discursos acadêmicos, na publicidade e nas diversas mídias a proliferação da ideia de que vivemos agora um regime inédito da cultura baseado na conectividade, na vida digital. Nesse contexto, o consumismo é exaltado como estratégia fundamental do tecnocapitalismo planetário, que transcende fronteiras, aproxima e identifica populações. O que é propagandeado é que a cibercultura se impóe, sedutoramente, como um mundo econômico de pleno direito onde, por meio das trocas infinitas nas redes, cada um constrói alegremente sua vida feliz.

A velocidade desses ciberacontecimentos e as mudanças deles decorrentes estão por toda parte e redefinem importantes domínios da vida social e cultural. A partir daí aumenta a sensação de insegurança, desestabilização e desorientação, sobretudo de pais e professores, com as crianças conectadas e, progressivamente, imersas nas redes colaborativas, na sequência de mutaçóes aceleradas que a comunicação digital não cessa em apresentar.

Nesse ambiente sempre camaleônico, a infância, tal como conhecemos, está mudando em decorrência de inúmeros fatores, como: o contato com diversas manifestaçóes multiculturais; a complexidade das transformaçóes presentes no cotidiano em relação à cidade, às famílias e às formas de interação com as tecnologias móveis; o hibridismo entre tradicionais e novos modos de brincar e se divertir; o fascínio e a ludicidade com os jogos eletrônicos, as redes sociais digitais e a conectividade etc. Tais fatores modificam modos de vida e sinalizam mudanças nas maneiras de entender a infância e o lugar que a criança ocupa nesse cenário em que os sistemas de significação e representação cultural se multiplicam.

Nesse contexto, muitos pontos de referências tradicionais coletivos e pedagógicos evaporaram, como certas visóes tradicionais de que a criança é inocente, pura, indefesa, incapaz de compreender o mundo sem a mediação do adulto (MANSON, 2001). Ao mesmo tempo, outros pontos de referência, sempre fluídos e deslizantes, não cessam de aparecer e estruturar o presente, como as noçóes de que a criança é ativa, quer opinar e mesmo decidir sobre seu desenvolvimento, formação, construçóes corporais, hábitos de consumo e lazer, mas, acima de tudo, viver cercada de objetos técnicos e aplicativos capazes de criar redes de conexóes com outras crianças e com o mundo, afinal, usar a rede significa acessar uns aos outros (TAPSCOTT, 2010). Conectadas e informadas 
as crianças moldam seus desejos e se colocam no mundo como seres capazes de opinar, discutir e tomar decisôes, e esse movimento não acontece sem conflitos.

Em toda parte estão pais e professores atentos, preocupados, desorientados, problematizando e discutindo experiências e dúvidas, questionando e querendo entender melhor essas dinâmicas que cercam, caracterizam e definem a "nova" cultura infantil. Perguntas como as que seguem são frequentes: sempre conectadas, imersas na rede, atentas as telas dos dispositivos móveis, as crianças estão se isolando, atrofiando a vida social, o contato sempre enriquecedor com o outro? As brincadeiras tradicionais estáo desaparecendo para dar lugar aos jogos eletrônicos? A ludicidade, marca característica e histórica da infância, ainda tem lugar em meio ao toque frenético das telas? De que maneira orientar crianças conectadas, que consomem informaçóes, saberes, produtos de muitas ordens e são parte integrante do cenário da existência luxuriante de um mundo que promete a felicidade de satisfações incontáveis e imediatas?

Essas questóes tem recebido toda sorte de respostas. Dessa forma, o objetivo deste artigo é problematizá-las e discuti-las, a partir do entendimento de que a cultura é sempre um modo de relação dos homens com as coisas do mundo, como defende Arendt (1997). Então, se quisermos saber como na atualidade muitas crianças se relacionam com as chamadas "novas coisas do mundo", devemos pensá-las em processo continuo de interação e participação com e na cultura tecnológica digital. O argumento principal defendido aqui é o de que as crianças que fazem parte da chamada "Geração Net", ou seja, que nasceram inseridas no contexto das tecnologias de informação e comunicação, participam ativamente do mundo digital, e vivem, sobretudo, por meio das tecnologias móveis, a conectividade. Nesse contexto, tocar em telas e brincar são modos especiais de construir subjetividades e existências, de viver e produzir a cibercultura infantil.

\section{A cibercultura infantil}

Nos últimos anos que concluíram o século XX, autores com Harvey (1999), Virilio (1984, 1999) e Lévy (1999) discutiram a condição da vida contemporânea centrada em perspectivas e experimentos de mobilização. $\mathrm{O}$ argumento era que a virada do século inaugurava uma época marcada pela velocidade que colocava tudo em circulação, em estado de urgência, alterando constantemente nosso campo perceptivo. Outro ordenamento do 
espaço e do tempo estava em questão. O longe e o perto se hibridizavam e a desterritorialização trouxe o espaço crítico, sempre mais encolhido e desprestigiado em funçáo de um novo ordenamento temporal promovido pelas tecnologias de informação e comunicação. A internet era percebida como a tecnologia do ordenamento do tempo e por ela outras organizaçóes se definiam como cultural, social, familiar.

Uma característica dessa fase da história das conexóes era a forma de viver o tempo, pois o que estava em questão eram as práticas que possibilitam a substituição da noção de tempo-duração por tempo-velocidade, isto é, pela instantaneidade das relaçóes sociais. O tempo vivido, das dobras do passado, presente e futuro, estava se transformando no tempo continuo do agora. $\mathrm{O}$ tempo das urgências, das volatilidades, é sempre uma perturbação da percepção, pois o horizonte deu lugar à realidade fugaz do tempo de aparição e desaparição das coisas e acontecimentos nas telas (KENSKI, 2013). Parece que com o tempo-velocidade quase tudo que pode ser considerado importante não passa de um brilho efêmero que condensa as experiências e as pessoas em movimentos siderais. A realidade passa a ser essa inusitada condição em que as relaçóes dos e entre os fenômenos é a imagem de um presente interminável em que cada um promove a sua performance existencial.

Tais relações cada vez mais íntimas entre os sujeitos e as tecnologias conectivas passaram a ser chamadas de cibercultura, entendida por Lévy (1999, p. 17) como "um conjunto de técnicas (materiais e intelectuais), de práticas, de atitudes, de modos de pensamento e de valores que se desenvolvem justamente com o crescimento do ciberespaço". O ciberespaço também passou a ser chamado simplesmente de "rede", um meio de comunicação surgido da interconexão mundial dos computadores.

A cibercultura é a expressão da aspiração de construção de um laço social, que não seria fundado nem sobre links territoriais, nem sobre relações institucionais, nem sobre relaçóes de poder, mas sobre a reunião de centros de interesses comuns, sobre o jogo, sobre o compartilhamento do saber, sobre a aprendizagem colaborativa, sobre processos abertos de colaboração. (LÉVY, 1999, p. 130). 
A cibercultura é a vida construída por meio das redes sociais digitais, em meio aos inúmeros processos interativos e participativos. Através dessas redes construímos subjetividades e sociabilidades, e redesenhamos nossos modos de ser e viver.

Para os autores já citados, o tempo proveniente das tecnologias comunicacionais, marcado pela interatividade online, altera o sentido cultural das nossas vidas. Essas percepçóes de um tempo real e de um espaço crítico sinalizam caminhos para a reestruturação do mundo dos sujeitos, especialmente das crianças, uma vez que esses elementos incorporam uma multiplicidade de sentidos e conotações que acabam por criar novas formas de interação entre as pessoas e destas com o mundo tecnológico. Esse processo de interação marca essencial da cibercultura, é cada vez mais complexo e plural. Ele seduz e envolve pessoas de todas as idades, principalmente, os mais jovens. A partir dai as relaçôes das crianças com os tempos tecnológicos (KENSKY, 2013), com as tecnologias digitais, passaram a ser definidas também como "cibercultura infantil”, que significa o mundo das crianças conectadas, seus hábitos, ideias e comportamentos como sujeitos que produzem e compartilham informaçôes na rede.

De modo geral, pais e educadores foram habituados a olhar a criança como alguém que recebe cultura. A cibercultura infantil, participativa, altera essa tradicional percepção quando diz que a criança é produtora e difusora de informaçóes e valores, que cria e divulga suas invençôes, que é agente ativo e propulsor de cultura (COSTA, 2009). Certa transição entre esses entendimentos tem, também, uma história e está associada a certos modos de como a infância foi tratada em épocas distintas (MANSON, 2001).

A infância é um sujeito social e histórico, e não uma simples entidade biológica (STEINBERG; KINCHELOE, 2004). A primeira fase de vida é moldada por vários fatores culturais, políticos, sociais, econômicos, familiares e pedagógicos que atuam sobre ela. Nesse processo, o adulto e a criança desenvolvem relaçóes de ensino e aprendizagens mútuos. A geração mais nova aprende comportamentos valorizados, cultuados e exaltados pelo seu grupo. A geração mais velha se desenvolve e se aprimora dentro dessa função socializadora. Essa história implica em conquistas e conflitos, pois ao mesmo tempo em que valores são produzidos e reproduzidos, são também desafiados.

Como sujeito social e histórico a criança vive e promove mudanças no seu meio. Atualmente, é a tecnologia digital que medeia cada vez mais as nossas 
relaçōes sociais. É ela que organiza o cotidiano. Ora, se é assim para todos, não pode ser diferente para as crianças. A cibercultura infantil deve, portanto, ser entendida para além dos aparelhos e dos usos, pois ela é, principalmente, o conjunto variado de saberes e atitudes, de conteúdos produzidos por e para os infantes. Segundo Jenkings (2009, p. 249), tal condição ressalta que "crianças estão ensinando crianças o que elas precisam saber para se tornarem participantes plenas da cultura da convergência”.

É um fato que atualmente as crianças já nascem imersas num mundo midiático, vivem com naturalidade as mais diversas relaçôes com as tecnologias digitais, fazem parte daquilo que Tapscott (1999) denominou de "a crescente e irreversível ascensão da Geração Net".

Com todas as desigualdades entre e nos países latino-americanos, em tantos lugares onde a cultura digital ainda é vivida de modo bastante limitado, pesquisas mostram que a conexão à internet é crescente e condiciona as relaçóes sociais. Dados apresentados, em 2012, pela Associação Latino-americana e do Caribe para registros de endereços Internet (LACNIC) revelam, por exemplo, que o alcance da Internet na América latina é de 40\%, com baixa presença de conexões consideradas banda larga. A expectativa é que esse índice cresça $60 \%$, em 2015, com mais açóes de fomento à inclusão digital (MENOS..., 2012). O aumento expressivo de acesso à internet previsto para os próximos anos mostra o quanto as dinâmicas para o gerenciamento da banda larga, fixa e móvel, mobilizam o mercado, os governos e a população em geral.

No Brasil, segundo o Ibope Media, em dados de dezembro de 2012, são 94,2 milhóes de pessoas com acesso a internet, o que coloca o Brasil como o quinto país mais conectado (ACESSO..., 2012).

Segundo Alexandre Sanches Magalhães, gerente de análise do Ibope//NetRatings, o ritmo de crescimento da internet brasileira é intenso. A entrada da classe C para o clube dos internautas deve continuar a manter esse mesmo compasso forte de aumento no número de usuários residenciais. (ESTATÍSTICAS..., 2012).

Dados de setembro de 2012 mostram que a quantidade de internautas brasileiros de 2 a 11 anos apresentou um aumento expressivo. "As crianças nessa faixa etária já representam $14,1 \%$ de toda a comunidade conectada no país, chegando a 5,9 milhóes" (CRESCE..., 2012). Nesse contexto, a conexão em 
tempo real e a vida online passam a ser vistas como um complexo cenário de ação infantil num espaço-tempo de comunicação, socialização e aprendizagem.

Tapscott $(1999,2010)$ define a infância no século XXI como a primeira a nascer cercada pela mídia digital. Essa infância é chamada por ele de "Geraçẫo Net", uma geração que nasce respirando tecnologias e, o mais importante, é autora no mundo digital. "Inseridas na cibercultura, as crianças constroem diferentes percursos e ações, pois são cada vez mais autônomas e independentes" (MENEZES; COUTO, 2010). Computadores, tablets, smartphones não causam estranhezas, e com muita "naturalidade" essas crianças descobrem como se comunicar e fazer amizades por meio da conversação online e trocas frequentes de mensagens. Aprender, brincar e se comunicar, produzir e difundir narrativas de suas experiências, e desejos e sonhos também fazem parte do mundo infantil conectado. Nesse sentido, para além de qualquer possível sensação de estranheza, essas crianças consideram os dispositivos tecnológicos e as chamadas novas tecnologias digitais como verdadeira extensão de si mesmas.

Diferentemente de muitos adultos, para essas crianças a vida online parece sem segredos, muito fácil, sedutora e lúdica. Cada dispositivo é tratado com intimidade, com afetividade, pois é um "amiguinho" com quem se pode brincar e fazer coisas extraordinárias. Esse fazer extraordinário significa se relacionar com outras crianças e, claro, com adultos. Como escreve Girardello (2008, p. 135):

Podemos esperar que, com o tempo e a presença cada vez maior de espaços multimídias na escola [e em casa], os meios digitais tendam a perder a aura que de certo modo ainda os distancia da argila, dos pincéis e dos lápis de cor - distancia que tende a ser sentida [...] pelos adultos [...]. Para as crianças hoje recém-chegadas ao mundo, que não possuem perspectivas históricas, e que têm acesso fácil ao computador, ele é desde já primordialmente um brinquedo, ou um espaço onde se brinca.

Essa intimidade infantil com a cultura digital é potencializada com o fato de que, como as crianças, as máquinas, programas e linguagens de informática e comunicação são dinâmicas, velozes, interativas e de fácil acesso. Devido essa relação, Tapscott (2010) destaca que a base das novas geraçóes é a interatividade, pois elas buscam ser ativas e náo apenas espectadoras ou ouvintes. "Não observam apenas, mas participam, perguntam, discutem, 
argumentam brincam, compram, criticam, investigam, ridicularizam, fantasiam, procuram e informam. A regra da vida conectada é ser livre para inventar, criar, experimentar" (MENEZES; COUTO, 2010). Essas açôes parecem sintetizar modos de viver a conectividade.

Essa geração de jovens e adolescentes, incluindo crianças em tenra idade, cria comunidades virtuais, desenvolvem softwares, fazem amigos virtuais, vivem novos relacionamentos, simulam novas experiências e identidades, encurtam as distâncias e os limites do tempo e do espaço e inventam novos sons, imagens e textos eletrônicos. Enfim, vivem a cibercultura (FERREIRA; LIMA; PRETTO, 2005, p. 247).

A cultura digital está a favor das crianças, o que possibilita e potencializa as condiçôes intelectuais para que possam participar da mídia digital e se reconhecerem, cada vez mais, como autoras nesse ambiente. As crianças conectadas são pioneiras na sociedade do imaginário tecnológico digital, pois tem a impressão de estar criando seu próprio terreno de aventuras, de poder inventar alguma coisa e se diferenciar das geraçóes anteriores, sem ter que se justificar. Talvez seja neste ponto que reside a grandeza e os principais valores da cibercultura infantil: liberdade, participaçáo, colaboraçáo, entretenimento e inovação (LIPOVETSKY; SERROY, 2011).

Liberdade para escolher e experimentar de muitas maneiras coisas novas. Tal liberdade é acentuada na rede porque nela, no tempo-velocidade, quase tudo está disponível e pode ser acessado para o desenvolvimento pessoal ou de grupo. $\mathrm{O}$ acesso é participativo e colaborativo porque as pessoas não se contentam em consumir informaçóes disponíveis, elas querem contribuir, emitir suas opinióes, envolver-se nos debates e ajudar para que outras pessoas possam solucionar seus problemas. Esse processo é marcado pelo entretenimento e ludicidade e as vivências parecem sempre divertidas. E, talvez o mais importante, tudo que já está feito e disponível é considerado como inacabado e insuficiente. Essa mentalidade impulsiona a criação e a inovação de linguagens programas, aplicativos, redes de colaboração, cogniçáo conectiva, o que, consequentemente, gera outros produtos, consumo e mais divertimento. E, náo raro, vemos o surgimento de novas profissóes e possibilidades de "emprego" para crianças e adolescentes. Algumas viram celebridade na rede, desenvolvem 
produtos, fundam empresas e ganham milhóes em pouquíssimo tempo. Esse imaginário, alimentado por alguns casos reais, mobiliza muita gente grande, mas principalmente os pequenos, afinal, parece que estamos todos atrás de visibilidade, fama e sucesso imediato.

Tal condição de vida altera significativamente tradicionais perspectivas e receios que faziam, e de certo modo ainda fazem, parte do mundo menos conectado da maioria dos adultos, pais e professores. Umas dessas principais mudanças é que a mídia agora não é mais algo que se consome, mas aquilo que se produz e difunde, ela deixa de ser influenciadora e condicionadora de tendências, para solicitar, exaltar e festejar a participação e a colaboração, instaurando, assim, uma economia da dádiva entre os internautas. Criatividade e generosidade são valores típicos da era das conexões e a cibercultura infantil não cessa de exaltar esses valores fundamentais. Shirky (2011) defende que a cultura da generosidade mostra os meios que temos para fazer a diferença e melhorar o mundo. A conectividade exige e valoriza esse fazer com o outro. É desse modo que a cibercultura infantil diz que a criança é criadora, colaboradora e participa de todo o processo de produção e difusão cultural. Nessas produçôes, as crianças interagem com as coisas do mundo, praticando formas especificamente infantis de inteligibilidade, representação e simbolização (FANTIN, 2008).

Afirmar que a criança é produtora de cultura pode ser desconfortável para muita gente. Mas é preciso considerar que grande parte das produções culturais das crianças é permeável à cultura das mídias digitais, dados os interesses comerciais das grandes corporações de mídia e entretenimento (COUTO et al, 2008). As empresas que querem conquistar o público infantil não mostram mais seu produto na televisão ou em uma só mídia, elas estão criando mundos virtuais onde as crianças interagem com outros usuários e com personagens.

Dessa forma, não se trata mais de apenas consumir, mas de participar do processo de criação, publicidade e comercialização de um produto ou de uma ideia; e também de opinar, avaliar, criticar as criaçóes e ter a liberdade para criar. Não é por acaso que as redes sociais digitais estão repletas de narrativas textuais, fotográficas e videográficas feitas por crianças, e com cada vez menos idade elas criam aplicativos que fazem sucesso e "viram febre" entre consumidores.

A cibercultura infantil presume, pelas razóes já expostas, que a criança não é frágil, boba ou ingênua. Ao contrário, o que é dito e exaltado é que ela sabe - e sabe muito - , é capaz de escolher, opinar, criar e consumir. Não é 
mais um infante, cuja etimologia remete àquele que não fala. Fazer parte da "geração net" é tomar posse da palavra, da escrita, dos sons e das imagens. Agora a criança é um ser pleno, pois na experiência do mercado, do consumo e do entretenimento ela pode escolher e criar produtos e serviços, opinar sobre tudo, ser a imagem sedutora num mundo de imagens. A partir daí, as opinióes das crianças são cada vez mais consideradas e respeitadas pelos adultos, pelos pais e professores. Elas opinam e decidem sobre o consumo, o lazer, os equipamentos eletrônicos, as viagens, ou mesmo quando certos produtos não são voltados pra elas, como um carro, pois tem acesso à variados tipos de informação pela televisão e, sobretudo, pela internet (SIBILIA, 2012).

Tudo isso pode significar que parte da subjetividade familiar e pedagógica foi substituída pela subjetividade midiática que estimula e organiza a existência conectada. Talvez essa mudança explique um pouco por que tantos pais e professores estáo desorientados e devem aprender a educar a partir de uma negociação contínua com essa geração de crianças conectadas (LIPOVETSKY; SERROY, 2011). Sendo assim, a cibercultura infantil pressupõe esse intenso diálogo entre adultos e crianças. Se tradicionalmente o mundo do adulto se opunha ao da criança, agora ele se aproxima e de muitos modos se confunde. A criança não é mais vista como um estado de deficiência em relação ao adulto, ela está conectada, informada, cheia de opinióes e disposta a colaborar com outras crianças e com os adultos - em muitos casos, sobretudo quando envolvem os usos das tecnologias digitais, elas sabem mais do que eles. As crianças são as mais perfeitas traduçóes de eficiências multifacetadas, e boa parte delas é dada pelo modo colaborativo de viver.

Existe, pois, na cibercultura infantil, um saber perceptivo e conectivo, marcado pela fugacidade e constante renovação, que pode possibilitar outros exercícios de cidadania e de consciência. Se parte do ideal transmissivo de conhecimentos ruiu é porque, talvez, não houve mais ensino fora dessa negociaçấo, fora do diálogo contínuo entre os sujeitos que aprendem e ensinam simultaneamente. É esse diálogo contínuo que desenvolve e estimula as relaçôes, marcadas por muitos e diferentes tipos de afinidades, que cada um preserva e escolhe para viver. Desse modo, diante do apelo do consumo de imagens, mercadorias e opinióes observamos que certos esforços conservadores para proteger noçôes tradicionais de infância são predestinados ao fracasso, pois não podemos proteger, limitar ou afastar as crianças do conhecimento de mundo que a cibercultura torna fascinante, irresistível e facilmente acessível. 
Um dos aspectos importantes para a popularização da cibercultura e da cibercultura infantil é a convergência de mídias, que se trata do fluxo de conteúdos através de múltiplos suportes (COUTO; SILVA, 2008). Nesse momento, as velhas e as novas mídias se colidem, a mídia corporativa e a mídia alternativa se cruzam, o poder do produtor de mídia e o poder do consumidor interagem de maneiras imprevisíveis. Essa cultura da convergência é um dos pontos emblemáticos da cultura lúdica infantil, que nesses tempos se desenha e opera em redes integradas de comunicação. Em aparelhos cada vez menores e de fácil manuseio, na palma da mão dos pequenos um mundo de desenhos animados, filmes, jogos eletrônicos, livros e revistas, sites e páginas pessoais e institucionais, músicas e ambientes para todo tipo de conversação magicamente se desvela e organiza o cotidiano pela lógica do divertimento, do encanto e do prazer.

Segundo Sarmento (2004), essa rede de fluxo segundo Sarmento (2004), aciona e mobiliza, de modo lúdico, outras articulaçôes cognitivas, pois embaralha diversos tipos de narrativas, sempre modificadas e acrescidas pela participaçáo infantil. O texto matricial dilui-se por completo e náo possui espaço ou funçáo definida; está em meio a muitos outros textos e textualidades que o reescrevem, dando-lhe outros sentidos e arrancando-lhe da sua condiçáo de origem. Na ausência de um texto original ou principal, a cultura lúdica, que se configura nessa rede transmídia, é tecida no entrecruzamento de informaçóes, saberes e significados que circulam, simultaneamente, em diversos suportes tecnológicos cujas narrativas se complementam.

Ao fazer parte das conexões, as crianças passam a ser usuárias e, ao mesmo tempo, construtoras de uma complexa realidade que possui denominaçôes e características próprias em mundos de significados, símbolos, imagens e informaçôes. A internet é um mundo que as crianças "controlam", pois é elas mesmas produzem e dão significados. O lugar da brincadeira também é também o lugar das mais fascinantes e sedutoras descobertas.

Tapscott (2010) argumenta que, por meio do toque lúdico nas telas, as crianças estão mudando tudo. Elas não se preocupam com os meandros de uma operação, simplesmente tocam e fazem as coisas acontecerem nas telas diante de si. Essas ações, sempre aceleradas e divertidas, são simplesmente parte da vida. Acabou o tempo de "assistir" aos acontecimentos, como se fazia diante da televisão, sem responder ao que se via. Agora só faz sentido acessar informaçôes ou desenvolver qualquer tipo de brincadeira se estivermos conectados com os amigos, não necessariamente num mesmo aposento, mas online, pois é 
conectado aos outros que promovemos as trocas importantes e necessárias capazes de dinamizar a vida e produzir a "nossa" cultura.

Outra característica importante desse modo de vida típico da cibercultura infantil - e que de certa maneira poderia estimular fascinantes processos da educação formal e não formal - é o fato de que as crianças conectadas se tornam investigadoras. De acordo com seus interesses, "futucam", "cutucam", procuram e investigam as informaçóes e os conteúdos que desejam. E quando buscam informação ou entretenimento transformam tudo em conversa na rede. A conversaçáo em rede, esses conjuntos de pensamentos, as opinióes e os interesses pessoais representam mais que liberdade, são geração de conteúdos (RECUERO, 2012).

Para as crianças, a conexão abre espaço para um mundo sem barreiras, que solicita e valoriza as experiências pessoais e as trocas coletivas. Nesse sentido, elas vivem num mundo que festeja as mixagens e incentiva que cada sujeito contribua do seu modo com as discussóes e soluçóes de problemas. As vidas conectadas, as misturas incessantes de informaçóes e conteúdos diversos, são experiências essencialmente lúdicas, pois as crianças se sentem como alguém que faz algo acontecer, que participa, interage e faz parte do jogo. Elas são agentes ativos e imprescindíveis nas tramas dos acontecimentos.

Segundo Brougère (1995), a mídia digital desempenha nas sociedades ocidentais um papel considerável transformando a vida e a cultura lúdica das crianças, que é simbólica e deve ser entendida dentro de um movimento global no qual está inserida. Antes de criticar o papel da televisão, da internet e das demais tecnologias nos dias atuais, a cultura de rede fornece às crianças e acolhe delas conteúdos diversos para suas brincadeiras.

Assim, a cibercultura é marcada pela convergência midiática e a cibercultura infantil pelo hibridismo de práticas e descobertas lúdicas. Não é verdade que as brincadeiras tradicionais desapareceram e que a ludicidade foi danificada porque as crianças vivem isoladas com seus "aparelhinhos" eletrônicos. As tradicionais práticas lúdicas não foram abandonadas em função de uma vivência em rede, considerada nova e atual, mas as reconfiguraçôes fazem aparecer outras maneiras de brincar, dão outros significados e sentidos ao brincar e a própria ludicidade.

Não se trata de um mundo binário, de escolhas entre uma coisa e outra, colocadas sempre em oposição, mas de um movimento sideral. A cibercultura 
infantil também é lugar de mixagens e coexistências de práticas e modos de vida. Nela as crianças convivem com um mundo, que é também lúdico, onde tudo acontece ou pode acontecer em diversas misturas e experimentaçóes, tudo ao mesmo tempo, simultaneamente. Essas misturas e experimentaçôes, em grande parte, são as diferentes maneiras de brincar que marcam a atualidade. Tocar telas e brincar são a mesma coisa (MENEZES; COUTO, 2012).

A vida conectada permite às crianças experiências ilimitadas que ultrapassam a educação familiar e escolar. Ao viver o tempo-aceleração elas podem circular por ambientes diversos de maneira impensáveis tempos atrás. É preciso considerar a força extraordinária da mobilidade que organiza a vida infantil. Como escreve Capparelli (2002, p. 137):

Em vez das crianças serem retiradas do espaço público devido à violência, as dificuldades de transportes nas grandes cidades ou os perigos que cada família enxerga além da porta da casa ou dos portóes do condomínio residencial, agora essa criança de dentro de casa participa do espaço exterior à esfera doméstica. Em suma, nessas comunidades criam-se novas formas de relacionamento e de mobilidades, com suspensão do confinamento da infância. As crianças vão agora às praças e ao carrossel virtual.

As tramas atraentes da conexão fazem da cibercultura infantil o lugar das delícias transmidiáticas. Essa rede eletrônica, aberta e sem fios, à qual cada um se conecta quando quer, para o triunfo narrativo, seduz pelo prazer. $O$ fato é que, mesmo nas regiōes mais pobres, os circuitos integrados promovem crianças proativas. E aqui todos nós, crianças e adultos, pais e professores, devemos aprender a conviver com a volatilidade inerente ao tempo-velocidade das subjetividades conectadas. Essa volatilidade deve ser vista como valor positivo, pois através dela renovamos em cada segundo a existência. Essas produçôes narrativas são manifestaçóes culturais estruturadoras e lúdicas da infância na cibercultura.

\section{Algumas conclusões}

As discussōes propostas e os argumentos desenvolvidos até aqui, apontam para um conjunto de conclusóes das quais desejo destacar três: a primeira é 
que as crianças brincavam com a areia da praia, jogavam bola, participavam de batalhas, arrumavam casinhas e enfeitavam bonecas. $\mathrm{Na}$ cibercultura infantil continuam com todas essas brincadeiras, agora integradas ou vivenciadas por meio de telas. É preciso destacar e enfatizar essa condição recente dos modos de brincar. As telas não são em si a brincadeira, são os meios pelos quais as conexões $\mathrm{e}$ as brincadeiras acontecem. Com a conectividade, $\mathrm{o}$ acesso às informaçôes e o desenvolvimento das relações humanas se tornaram mais intensas. Em velocidades crescentes os experimentos, as criaçôes e os imaginários infantis se ampliaram e, provavelmente, ficaram mais ricos e fecundos.

Essa conclusão encaminha a segunda: a cibercultura infantil tem os seus paradoxos. Nada nela é excludente, mas diferente, múltiplo. Não faz sentido dizer que a infância acabou, ou que as crianças não sabem mais brincar, que ficam isoladas e presas em casa, que só sabem ver e estar no mundo por intermédio de suas telas preferidas. É preciso compreender o teor das mixagens, dos hibridismos que marcam a vida contemporânea. Esses hibridismos atualizam os modos de ser, brincar e viver de muitas e diferentes maneiras. Embora milhares de crianças estejam cada vez mais conectadas, parece que elas seguem usando também estratégias culturais tradicionalmente associadas à infância, digamos, tradicional, e hibridizando todas elas, afinal, ninguém vive conectado o tempo todo, pelo menos por enquanto. Existe um movimento incessante entre a vida online e a vida offline. É nesse entremeio que encontramos os nossos mais belos desafios, assim como as mais intensas alegrias.

A terceira e última conclusão é que são equivocadas as constatações apressadas daqueles que dizem que as crianças de hoje ficam "grudadas" no computador, nos tabletes, srtphones e não sabem mais brincar. O que é defendido aqui é que fascinação delas por esses aparelhos e telas se dá porque por meio delas estabelecem contatos e relações com outras crianças, jovens e adultos, e porque criam comunidades, fazem e mantém amizades, narram suas histórias, ou seja, brincam o tempo todo. $\mathrm{O}$ prazer de brincar talvez seja até mais intenso, pois podem frequentemente experimentar sensaçóes diferentes no tempo-velocidade do agora. A cibercultura infantil não encurta a infância, não sacrifica as brincadeiras, não torna crianças em adultos chatos e precoces. Inseridas no mundo digital, vivendo criativamente a promoção da cultura em rede, as crianças fundem e confundem sentidos diversos do brincar. Imaginam e criam possibilidades de experimentar cada vez mais sensações. Tocar telas é brincar. Esse é um jeito especial de viver, uma expressão de liberdade repleta de encantos e felicidades. 
As subjetividades infantis desenvolvidas com os usos dos dispositivos digitais indicam que o diálogo contínuo com pessoas em rede, por meio do compartilhamento e da generosidade, apontam diferentes modos de promover a cibercultura, assim como outras maneiras de articular as relações das crianças entre si e destas com os adultos nos muitos processos de ensino-aprendizagem. Entender tais procedimentos é o primeiro passo para melhor orientar as crianças em meio às dispersóes possivelmente geradas diante dos excessos de informaçóes típicos da rede. Afinal, um dos grandes desafios da nossa época, e também uma responsabilidade dos adultos com a educação dos pequenos, é ajudá-los a selecionar e atribuir significados a tudo aquilo que nas telas aparecem e desaparecem em fluxos e brilhos contínuos. Valorizar e dar mais densidade às experiências, orientar para usos mais seguros da internet sáo práticas urgentes que devem fazer parte do nosso cotidiano conectado.

Habituadas a viver no tempo de exposição em rede, as crianças conectadas valorizam o estar em comunicação com os amigos. Esse "estar junto" é fundamental para estabelecer laços e sociabilidades que apenas aos olhos de certos adultos podem parecer estranhos ou superficiais. Estimuladas pela cibercultura, tocar telas, relacionar com outras pessoas e brincar são modos lúdicos que as crianças encontram para elaborar a vida em meio às alegrias e prazeres privados e coletivos nos domínios da rede. Na era das tecnologias de conexão, tocar e brincar são prazeres em movimento que se apoderam ludicamente das existências.

\section{REFERÊNCIAS}

ARENDT, Hannah. Entre o passado e o futuro. 4. ed. São Paulo: Perspectiva, 1997.

ACESSO à internet no Brasil atinge 94,2 milhôes de pessoas. Ibope, São Paulo, 17 dez. 2012. Disponível em: <http://www.ibope.com.br/pt-br/ noticias/paginas/acesso-a-internet-no-brasil-atinge-94-milhoes-de-pessoas. aspx>. Acesso em: 27 mar 2013.

BROUGÈRE, Gilles. Brinquedo e cultura. São Paulo: Cortez, 1995.

CAPPARELLI, Sérgio. Infância digital e cibercultura. In: PRADO, José Luiz Aidar (Org.). Crítica das práticas midiáticas: da sociedade de massa às ciberculturas. São Paulo: HackerEditores, 2002. p. 130-145. 
COSTA, Belarmino Cesar Guimarães da. Ambiente das mídias digitais: reflexões sobre comunicação e comunicação. Perspectiva, Florianópolis, SC, v. 27, n. 1, p. 141-164, jan./jun. 2009. Disponível em: <https://periodicos. ufsc.br/index.php/perspectiva/article/view/2175-795X.2009v27n1p141>. Acesso em: 27 abr. 2013.

COUTO, Edvaldo Souza et al. Da cultura de massa às interfaces na era digital. Revista da FACED, Salvador, BA, v. 14, p. 105-118, jul./dez. 2008. Disponível em: <http://www.portalseer.ufba.br/index.php/entreideias/ article/view/3216/2657> Acesso em: 21 mar. 2013.

COUTO, Edvaldo Souza; SILVA, Valdirene Cássia da. Convergência culturalmidiática: as tecnologias e a fruidez da juventude na cibercultura. In: ENCONTRO DE ESTUDOS MULTIDISCIPLARES EM CULTURA, 4., 2008, Salvador. Anais... Salvador: UFBA, 2008. p. 1-14. 1 CD-ROM.

CRESCE quantidade de crianças na internet no Brasil. Olhar Digital, 6 set. 2012. Disponível em: <http://olhardigital.uol.com.br/noticia/crescequantidade-de-criancas-na-internet-no-brasil/28914>. Acesso em: 1 maio 2013.

ESTATÍSTICAS, dados e projeções atuais sobre a Internet no Brasil. To Be Guarani, 2012. Disponível em: <http://tobeguarany.com/internet_no_brasil. php>. Acesso em: 3 maio 2013.

FANTIN, Monica. Do mito de Sísifo ao vôo de Pégaso: as crianças, a formação de professores e a escola estação cultura. In: FANTIN, Monica; GIRARDELLO, Gilka (Org.). Liga, roda, clica: estudos em midia, cultura e infância. São Paulo, Papirus, 2008.

FERREIRA, Simone de Lucena; LIMA, Maria de Fátima M.; PRETTO, Nelson De Luca. Mídias digitais e educação: tudo ao mesmo tempo agora o tempo todo. In: BARBOSA FILHO, André; CASTRO, Cosette; TAKASHI, Tome (Org.). Mídias Digitais: convergência tecnologica e inclusão digital. São Paulo: Paulinas, 2005. p. 225-256.

GIRARDELLO, Gilka. Produção cultural infantil diante da tela: da TV à internet. In: FANTIN, Monica; GIRARDELLO, Gilka (Org.). Liga, roda, clica: estudos em mídia, cultura e infância. São Paulo: Papirus, 2008. 
HARVEY, David. Condição pós-moderna: uma pesquisa sobre as origens da mudança cultural. São Paulo: Loyola, 1999.

JENKINS, Henry. Cultura da Convergência. 2. ed. São Paulo: Aleph, 2009.

KENSKI, Vani Moreira. Tecnologias e tempo docente. Campinas, SP: Papirus, 2013.

LÉVY, Pierre. Cibercultura. São Paulo: 34, 1999.

LIPOVETSKY, Gilles; SERROY, Jean. A cultura-mundo: resposta à uma sociedade desorientada. Tradução de Maria Lucia Machado. São Paulo: Companhia das Letras, 2011.

MANSON, Michel. Jouets de toujours. Paris: Libraire Arthéme Fayard, 2001.

MENEZES, José Américo; COUTO, Edvaldo Souza. Clicar e brincar: o lúdico na cibercultura infantil. In: ARAPIRACA, Mary; BELTRÃO, Lícia Freire; SUZART, Cleverson. Estudos e passagens do Proinfantil na Bahia. Salvador: EDUFBA, 2012. p. 145-152.

MENEZES, José Américo; COUTO, Edvaldo Souza. Clicar e brincar: o lúdico na cibercultura infantil. In: ENCONTRO DE ESTUDOS MULTIDISCIPLINARES EM CULTURA, 6., 2010, Salvador. Anais... Salvador, BA: UFBA, 2010. Disponível em: <http://www.cult.ufba.br/ wordpress/24368.pdf>. Acesso em: 25 mar 2013.

MENOS da metade da América Latina tem acesso à Internet. Convergência Digital, 11 maio 2012. Disponivel em: <http://convergenciadigital.uol.com. $\mathrm{br} /$ cgi/cgilua.exe/sys/start.htm?infoid=30391\&sid=8\#.UvpsW2JdWE4 $>$. Acesso em: 3 maio 2013.

RECUERO, Raquel. A conversação em rede: comunicação mediada por computador e redes sociais na internet. Porto Alegre, RS: Sulina, 2012.

SARMENTO, Manuel Jacinto. As culturas da infância nas encruzilhadas da segunda modernidade. In: SARMENTO, Manuel Jacinto; CERISARA, Ana Beatiz (Org.). Crianças e miúdos: perspectivas sociopedagógicas da infância e educação. Porto, PT: ASA, 2004.

SHIRKY, Clay. A cultura da participação: criatividade e generosidade no mundo conectado. Rio de Janeiro: Zahar, 2011. 
SIBILIA, Paulo. Redes ou paredes. A escola em tempos de dispersão. Rio de Janeiro, Editora Contraponto, 2012.

STEINBERG, Shirley; KINCHELOE, Joe (Org.). Cultura Infantil: a construção da infância. 2. ed. Rio de Janeiro: Civilização Brasileira, 2004.

TAPSCOTT, Dan. Geração Digital: a crescente e irreversível ascensão da Geração Net. São Paulo: Makron Books, 1999.

TAPSCOTT, Dan. A hora da geração digital: como os jovens que cresceram usando a internet estáo mudando tudo, das empresas aos governos. Rio de Janeiro: Agir Negócios, 2010.

VIRILIO, Paul. L'espace critique. Paris, Christian Bourgois Editeur, 1984.

VIRILIO, Paul. A bomba informática. São Paulo: Estação Liberdade, 1999. 


\section{La infancia y el jugar en la cultura digital}

\section{Resumen}

A partir de los estudios que discuten la cibercultura, la infancia y el jugar en la cultura digital el artículo reflexiona sobre la cultura lúdica infantil en la era de las conexiones. El camino recorrido fué buscar pistas em relación a las características más marcantes de la cibercultura para luego observarlas en la cultura lúdica infantil. El principal argumento es de que los nińos que hacen parte de la llamada Generación-Net, que nacieron inseridos en el contexto de estas tecnologías de información y comunicación participan activamente del mundo digital, viven, sobre todo, por medio de las tecnologías mobiles, la conectividad. En este contexto, tocar en las pantallas y jugar son modos especiales de construir subjetividades y existencias, de vivir y producir la cultura infantil. El artículo concluye que el toque en las más diversas pantallas, muchas de ellas en la palma de la mano, traducen mucho de lo que es jugar y de lo lúdico en la actualidad. Tocar en pantallas digitales es un aspecto expresivo del modo lúdico que los niños encuentran para elaborar la vida por medio de alegrías y placeres privados y colectivos en los dominios de la red.

Palabras claves: Infancia. Ludicidad. Cultura digital.

\section{Childhood and play in the digital culture}

\section{Abstract}

From studies addressing cyberculture, childhood and play in the digital culture, this paper reflects on the children's play culture in the connection era. The path traced started with the search for the most remarkable characteristics of cyberculture and went on to observe them in the children's play culture. The main argument is that children belonging to the so-called Net Generation, who were born in the context of information and communication technologies, actively participate in the digital world and experience connectivity, particularly by means of mobile technologies. In such context, touching screens and playing are special ways of constructing subjectivities and existences, living and producing children's culture. The paper has concluded that touching different kinds of screens, many of them on the palm top, translate much of what playing and playful mean today. Touching digital screens is the most expressive playful way that children have found to elaborate life through private and collective amusements and pleasures in the web realm.

Keywords: Childhood. Playfulness. Digital Culture. 


\section{Edvaldo Souza Couto}

E-mail: edvaldosouzacouto@gmail.com

Recebido em: 5/5/2013

Versáo final recebida em: 7/8/2013

Aprovado em: 14/8/2013 